\title{
Effect of magnetic fluid hyperthermia on lung cancer nodules in a murine model
}

\author{
RUNLEI HU ${ }^{1}$, SHENGLIN MA ${ }^{1}, \mathrm{HU}^{1}{ }^{1}$, XIANFU KE ${ }^{2}$, \\ GUOQING WANG $^{1}$, DONGSHAN WEI ${ }^{1}$ and WEI WANG ${ }^{1}$ \\ ${ }^{1}$ Department of Thoracic Surgery, Hangzhou First People's Hospital; ${ }^{2}$ Laboratory Animal Center, \\ Zhejiang Academy of Medical Sciences, Hangzhou, Zhejiang 310006, P.R. China
}

Received March 3, 2011; Accepted August 5, 2011

DOI: $10.3892 / \mathrm{ol} .2011 .379$

\begin{abstract}
The purpose of the present study was to investigate the therapeutic effect of magnetic fluid hyperthermia (MFH) induced by an alternating magnetic field (AMF) on human carcinoma A549 xenograft in nude mice. An animal model of human lung cancer was established by subcutaneous injection of human lung cancer A549 cells in BALB/c nude mice. The xenograft mice were randomly divided into four groups and each group was treated with an injection of a different concentration of magnetic fluid: control, low-dose $(67.5 \mathrm{mg} / \mathrm{ml})$, medium-dose (90.0 mg/ml) and high-dose group $(112.5 \mathrm{mg} / \mathrm{ml})$, respectively. Following the injection ( $24 \mathrm{~h}$ ), the tumor was heated in an AMF for $30 \mathrm{~min}$. Tumor volumes were then measured every week. The therapeutic effect was assessed by measuring the tumor volume and weight. Pathological examination was performed with a light and electronic microscope following treatment. The temperature at the surface of the tumor in the low-, medium- and high-dose groups increased to $41.3,44.5$ and $46.8^{\circ} \mathrm{C}$, respectively. The tumor grew significantly slower in the medium- and high-dose groups (both $\mathrm{p}<0.05$ ) compared to the control group. Cytoclasis and apoptosis were detected under light and electron microscopy. In conclusion, MFH induced by AMF inhibited tumor growth and promoted apoptosis of human carcinoma A549 cells in a xenograft mice model.
\end{abstract}

\section{Introduction}

Lung cancer is one of the most common malignant tumors worldwide, and its incidence has increased in recent years. Current therapeutic options remain unsatisfactory for most patients. Surgical resection has been identified as the most effective method for the treatment of lung cancer, but it is only available for a small number of patients (1). Therefore, it is crucial to identify a new treatment method.

Correspondence to: Dr Shenglin Ma, Department of Thoracic Surgery, Hangzhou First People's Hospital, Hangzhou, Zhejiang 310006, P.R. China

E-mail: mashenglin@medmail.com.cn

Key words: magnetic fluid, hyperthermia, lung cancer
Magnetic fluid hyperthermia (MFH) is a thermal therapy using nanotechnology and hyperthermia, first reported by Jordan et al (2). These authors directly injected magnetic fluids into tumors and increased the temperature using an AMF through the Neel relaxation mechanism (3). Since the magnetic particles were directly injected into tumors, there was no distribution of magnetic particles in the periphery of normal tissues and the temperature of these tissues did not increase significantly. Thus, the hyperthermia specifically targeted the tumors. The efficacy of hyperthermia was demonstrated using MFH in animals with several types of tumors, such as B16 mouse melanoma, T-9 rat glioma, SMMC-7721 mouse hepatocarcinoma and BT-474 mouse breast cancer (4-7). This method was found to be effective in inducing the regression of tumors and increasing the lifespan of the animal. As a result, MFH appears to be a promising method for targeting malignant tumors, including lung cancer.

The present study investigated the feasibility of MFH for the treatment of lung cancer with a focus on the antitumor effects of hyperthermia.

\section{Materials and methods}

Magnetic fluids and AMF. Magnetic fluids (Anhui Jinke Magnetic Liquid Co., Ltd., Anhui, China) used in the experiment consisted of superparamagnetic iron oxide particles (core diameter 10-40 nm) dispersed in water. The weight fraction of the iron was $20 \%$ and the saturation magnetization of the particles was $360 \mathrm{G}$.

A high-frequency induction heating machine (Type SP-04AC; Shenzhen Power Supply Technology Co., Ltd., Guangdong, China) was used to provide an electric current through copper induction coils. The copper induction coils with a hallow structure could be cooled down by a circulation water system. The operation frequency of the magnetic field is $150 \mathrm{kHz}$ and the power consumption is estimated to be $4 \mathrm{~kW}$.

Cell lines and animals. Human lung cancer A549 cells were purchased from the Institute of Biochemistry and Cell Biology, Shanghai Institute of Biological Sciences, Chinese Academy of Sciences. Cells were cultured in RPMI-1640 medium supplemented with $10 \%$ heat-inactivated calf serum, penicillin 
Table I. Volume and mass inhibitory rates of lung cancer A549 cells in nude mice after treatment.

\begin{tabular}{lcccc}
\hline Groups & $\begin{array}{c}\text { Tumor volume } \\
\left(\mathrm{mm}^{3}, \text { mean } \pm \mathrm{SD}\right)\end{array}$ & $\begin{array}{c}\text { Volume inhibitory } \\
\text { rate }(\%)\end{array}$ & $\begin{array}{c}\text { Tumor mass } \\
(\mathrm{g}, \text { mean } \pm \mathrm{SD})\end{array}$ & $\begin{array}{c}\text { Mass inhibitory } \\
\text { rate }(\%)\end{array}$ \\
\hline Control & $831.0 \pm 126.2$ & - & $1.71 \pm 1.11$ & - \\
Low-dose & $713.2 \pm 157.1$ & $14.1^{\mathrm{a}}$ & $1.51 \pm 0.25$ & $11.7^{\mathrm{a}}$ \\
Medium-dose & $399.2 \pm 199.2$ & $51.9^{\mathrm{b}}$ & $0.93 \pm 0.40$ & $45.6^{\mathrm{b}}$ \\
High-dose & $247.3 \pm 102.0$ & $70.2^{\mathrm{b}}$ & $0.65 \pm 0.21$ & $62.0^{\mathrm{b}}$ \\
\hline
\end{tabular}

${ }^{\mathrm{a}} \mathrm{p}>0.05$ vs. the control group; ${ }^{b} \mathrm{p}<0.01$ vs. the control group.

$(100 \mathrm{U} / \mathrm{ml})$ and streptomycin $(100 \mathrm{mg} / \mathrm{ml})$, and grown in the presence of $5 \% \mathrm{CO}_{2}$ at $37^{\circ} \mathrm{C}$.

$\mathrm{BALB} / \mathrm{C}$ nude mice (female, 5-week-old) were purchased from the Shanghai Institute of Biological Sciences, Chinese Academy of Sciences. The animal experiments were performed according to the principles described in the Guide for the Care and Use of Laboratory Animals as promulgated by the Zhejiang Standing Committee of PNC.

Therapeutic effect of MFH on xenograft lung cancer. Xenograft tumors were induced by the subcutaneous injection of human lung cancer A549 cells under the right flank of nude mice. When the tumor diameter reached $0.6-0.8 \mathrm{~cm}$, the mice were divided into four groups $(n=8)$ : i) control group (sterile $0.9 \% \mathrm{NaCl})$, ii) low-dose group $(67.5 \mathrm{mg} / \mathrm{ml}$ $\left.\mathrm{Fe}_{3} \mathrm{O}_{4}\right)$, iii) medium-dose group $\left(90.0 \mathrm{mg} / \mathrm{ml} \mathrm{Fe}_{3} \mathrm{O}_{4}\right)$, and iv) high-dose group $\left(112.5 \mathrm{mg} / \mathrm{ml} \mathrm{Fe}_{3} \mathrm{O}_{4}\right)$. The magnetic fluid with half of the tumor volume was injected into the tumors. Following the magnetic fluid injection $(24 \mathrm{~h})$, the tumors of the mice in groups 2-4 were exposed to a high-frequency AMF for $30 \mathrm{~min}$. Tumor and rectal temperature were taken by an optical fiber probe (YF-200). After 45 days, the animals were sacrificed. The weight and volume inhibitory rates (IW and IV, respectively) of the tumors were calculated as: IW $=(1-$ the weight of the tumor of the experimental group/ the weight of the tumor of the control group) $\times 100 \%$; IV = ( 1 - the volume of the tumor of the experimental group/the volume of the tumor of the control group).

Histological analysis. One day after hyperthermia, 2 mice were randomly chosen from each group. After euthanizing the mice, tumors were collected and processed for histological analysis. Briefly, the tumors were fixed in $10 \%$ formalin, embedded in paraffin, sectioned and stained with H\&E.

The apoptosis of tumor cells was assessed under transmission electron microscopy (TEM). Tumors were harvested and dissected into $1-\mathrm{mm}^{3}$ specimens. Subsequently, the samples were fixed in $4 \%$ glutaraldehyde and cut into ultrathin sections $(70 \mathrm{~nm})$ to be examined under TEM.

Statistical analysis. To evaluate the significance of the overall differences in tumor volumes and tumor weights among the in vivo groups, statistical analysis was performed by analysis of variance (ANOVA). $\mathrm{P}<0.05$ was considered to be statistically significant. The tumor volume and weight data were expressed as the means \pm standard error on graphs.

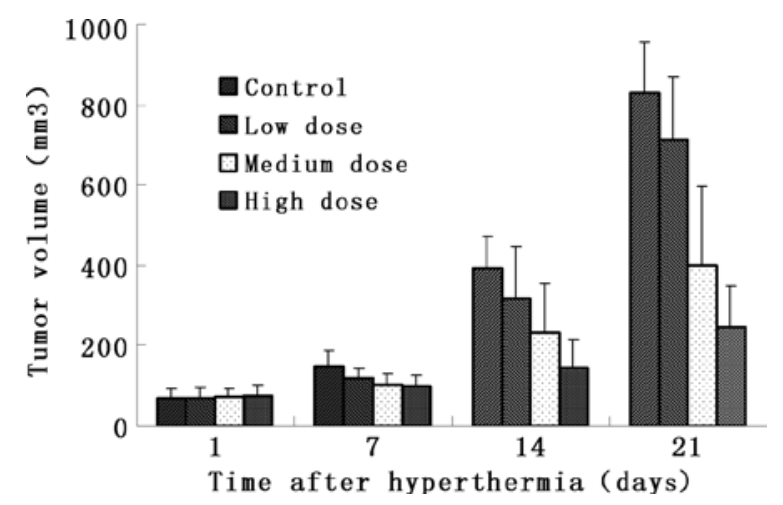

Figure 1. Time course of the tumor growth.

\section{Results}

Heat generation by magnetic fluids in AMF. The temperature rose rapidly within $5 \mathrm{~min}$ and remained stable after $10 \mathrm{~min}$. The average plateau temperature of groups $2-4$ was $41.3,44.5$ and $46.8^{\circ} \mathrm{C}$, respectively. The temperature of each group was maintained for $30 \mathrm{~min}$. The rectum temperature was maintained at $\sim 30.0 \pm 0.5^{\circ} \mathrm{C}$. These data demonstrate a specific magnetic hyperthermia.

Effects of hyperthermia on the tumors. Anatomical analysis showed that the tumors in the experimental groups became smaller (Fig. 1). The mass and volume inhibitory ratio of group 4 was 62.0 and $70.2 \%$, respectively, which was much higher than that of the remaining groups (Table I). Comparisons between the experimental and control groups revealed that groups 3 and 4 were markedly different from the controls $(\mathrm{p}<0.01)$, while there was no significant difference between group 2 and the control group $(\mathrm{p}>0.05)$.

Histological analysis. Histological examination in groups 3 and 4 revealed that there was an accumulation of black nanosized $\mathrm{Fe}_{3} \mathrm{O}_{4}$ particles at the stroma in the margin of the tumors. A number of tumor cells disappeared at the site adjacent to this accumulation, and a necrotic zone was found surrounding the material (Fig. 2).

Tumor apoptosis was observed under TEM. Apoptotic tumor cells were identified using characteristics such as karyopycnosis, chromatin margination and condensation. In group 4, the normal tumor cell structure disappeared. Karyorrhexis and karyolysis were evident (Fig. 3). 


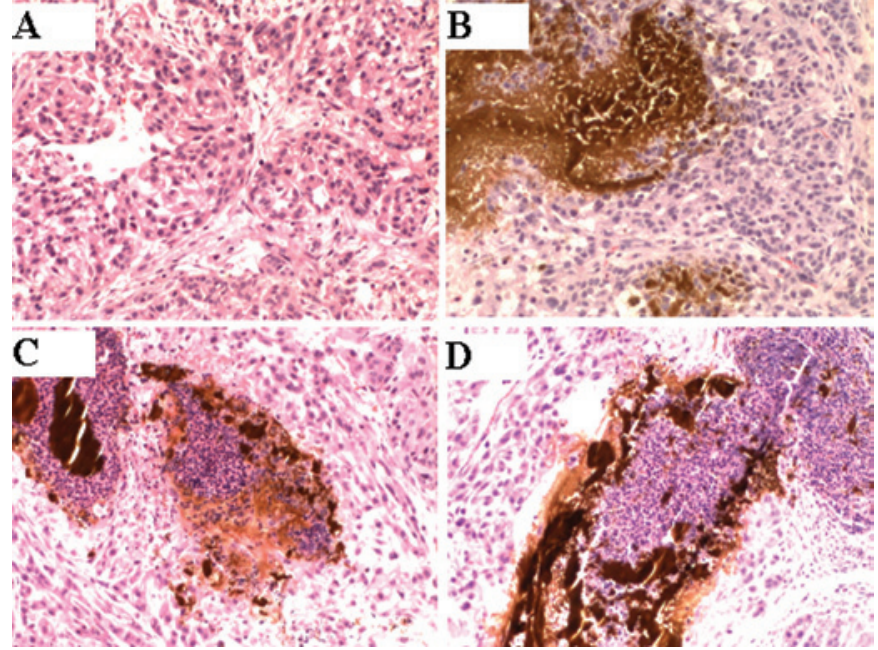

Figure 2. Changes in cell morphology were observed by light microscopy (H\&E staining, magnification, $\mathrm{x} 400$ ). (A) Control group. (B) Low-dose group; human carcinoma A549 cells exhibit no obvious changes. (C) Medium-dose group; most of the human carcinoma A549 cells had coagulation necrosis (light microscopy). (D) High-dose group; most of the human carcinoma A549 cells exhibited coagulation necrosis by light microscopy, whereas the necrotic area was wider than that in the medium-dose group.

\section{Discussion}

Empirical and clinical studies have indicated that heat plays a crucial role in human lung cancer (8). Despite the promising results, hyperthermia has yet to be established as a clinical routine treatment. This is not due to a general lack of efficacy, but rather due to the limitations of the current available techniques with respect to selectively targeting the tumor region and homogeneously distributing the heat within the tumor tissue.

Magnetically induced interstitial hyperthermia addresses these shortcomings, especially for deep-seated and poorly accessible tumors. Superparamagnetic biocompatible nanoparticles are directly injected into the tumor tissue where they are stimulated by an AMF to produce heat due to Brownian and Neel relaxation processes. Our method of MFH is capable of heating the tumor directly. During the hyperthermia, the average temperature of groups $2-4$ rose from 41.3 to $46.8^{\circ} \mathrm{C}$, and the rectum temperature was approximately $30.0^{\circ} \mathrm{C}$, allowing the operator to induce tumor cell apoptosis and necrosis without damaging the adjacent normal tissue.

The important finding from our study was the effect of MFH on lung cancer nodules in a murine model. A higher temperature potentially improved the therapeutic effect on lung cancer. When the strength of the magnetic field was kept stable, it resulted in a higher dose of the magnetic fluid, resulting in a more rapid increase in temperature and a higher maximum temperature. Comparisons between the experimental and control groups revealed that hyperthermia with intensity over a threshold level markedly reduced the mass and volume of the tumors, which could not be achieved by hyperthermia with intensity below the threshold level. Our results strongly suggest that the intensity of hyperthermia is crucial for the efficacy of the MFH therapy and a threshold level has to be achieved to obtain the expected efficacy of the therapy.

Notably, we found that the apoptotic rate increases with a higher temperature (9). Apoptosis is programmed cell
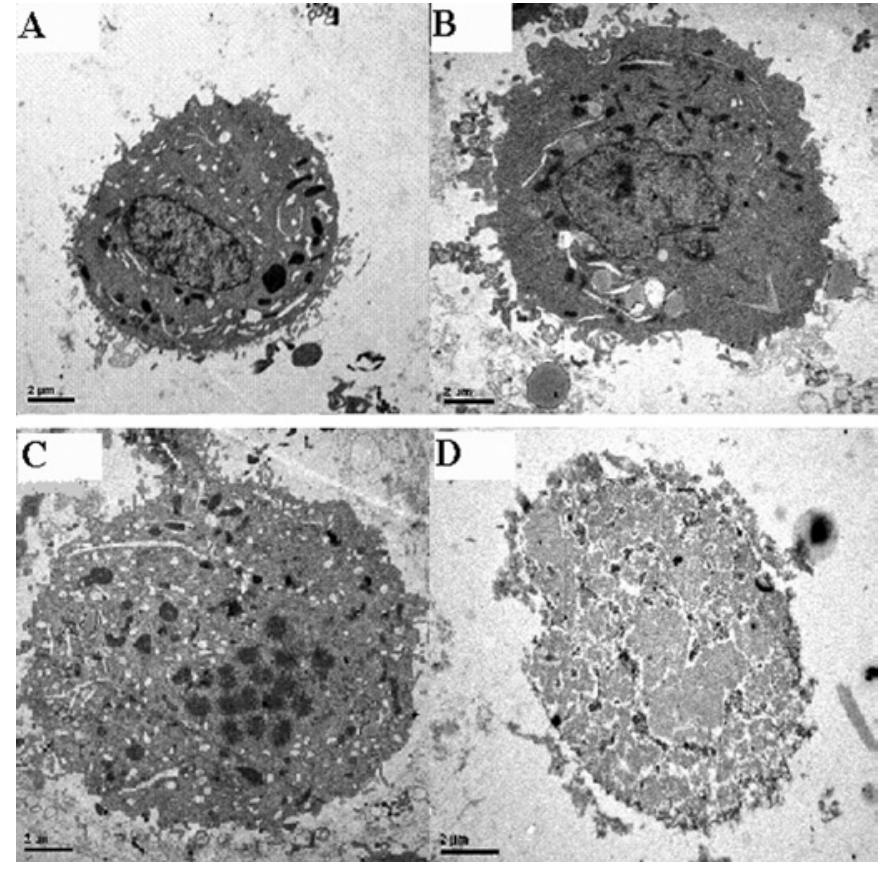

Figure 3. Changes in cell morphology were observed by electron microscopy (A) Normal human carcinoma A549 cells. (B) A549 cells exhibit no obvious changes. (C) A549 cells were observed to have margination and nuclear fragmentation. (D) Necrosis was observed. Magnification, x8,000.

death and is an important indicator of successful therapy for various types of cancer. Cells undergoing apoptosis demonstrate certain characteristic changes, including the formation of DNA fragments, chromatin margination, vacuolization of cytoplasm, shrinkage of cells and formation of apoptotic bodies $(10,11)$. The temperature of $42-46^{\circ} \mathrm{C}$ disrupts the enzymatic system and structure in tumor cells, induces apoptosis and subsequent necrosis. When the temperature was above $46^{\circ} \mathrm{C}$, numerous large necrotic areas were observed, and the nanometer granules were distributed in the interstitial matrix of tumors or were phagocytized by tumor cells. Necrosis, apoptosis, karyopycnosis, disintegration, karyorrhexis and karyolysis, as well as vacant nuclei were found in the tumor cells surrounding the granules.

In conclusion, MFH yielded favorable temperature elevation in mouse xenograft lung cancer tumors, created welldefined areas of apoptosis and necrosis and inhibited tumor growth. Further optimization of magnetic fluid and AMF parameters may allow for the testing of other animal models. This mini-invasive hyperthermia therapy appears promising for the treatment of lung cancer.

\section{Acknowledgements}

This study was supported by grants from the Medicine and Health Foundation of Zhejiang Province (Grant no. 2009A163), and the Science and Technology Development Foundation of Hangzhou (Grant no. 20080333B02).

\section{References}

1. Hammerschmidt S and Wirtz H: Lung cancer: current diagnosis and treatment. Dtsch Arztebl Int 106: 809-818, 2009. 
2. Jordan A, Wust P, Scholz R, et al: Effects of magnetic fluid hyperthermia (MFH) on $\mathrm{C} 3 \mathrm{H}$ mannary carcinoma in vivo. Int $\mathrm{J}$ Hyperthermia 13: 587-605, 1997.

3. Hildebrandt B, Wust P, Ahlers O, et al: The cellular and molecular basis of hyperthermia. Crit Rev Oncol Hematol 43: 33-56, 2002.

4. Ito A, Matsuoka F, Honda $\mathrm{H}$ and Kobayashi T: Antitumor effects of combined therapy of recombinant heat shock protein 70 and hyperthermia using magnetic nanoparticles in an experimental subcutaneousmurine melanoma. Cancer Immunol Immunother 53: 26-32, 2004.

5. Yanase M, Shinkai M, Honda H, Wakabayashi T, Yoshida J and Kobayashi T: Antitumor immunity induction by intracellular hyperthermia using magnetite cationic liposomes. Jpn J Cancer Res 89: 775-782, 1998.

6. Wang ZY, Song J and Zhang DS: Nanosized As2O3/Fe2O3 complexes combined with magnetic fluid hyperthermia selectively target liver cancer cells. World J Gastroenterol 15: 2995-3002, 2009.
7. Kikumori T, Kobayashi T, Sawaki M, et al: Anti-cancer effect of hyperthermia on breast cancer by magnetite nanoparticle-loaded anti-HER 2 immunoliposomes. Breast Cancer Res Treat 113: 435-441, 2009.

8. Jiang Z, Yan W, Ming J and Yu Y: Docetaxel weekly regimen in conjunction with RF hyperthermia for pretreated locally advanced non-small cell lung cancer: a preliminary study. BMC Cancer 7: 189, 2007

9. Chen GZ, Luo BD, Wang HQ, et al: Effect of hyperthermia on rat hipocampal pyramidal cell apoptosis in vitro. Di Yi Jun Yi Da Xue Xue Bao 23: 233-235, 2003.

10. Mathiasen I, Sergeev I, Bastholm L, Elling F, Norman A and Jäättelä M: Calcium and calpain as key mediators of apoptosislike death induced by vitamin D compounds in breast cancer cells. J Biol Chem 277: 30738-30745, 2002.

11. Barni S,Pontiggia P,Bertone V, Vaccarone R, Silvotti MG, Pontiggia $\mathrm{E}$ and Mathe G: Hyperthermia-induced cell death by apoptosis in myeloma cells. Biomed Pharmacother 55: 170-173, 2001. 